\title{
Solid and gaseous cerebral microembolization during off- pump, on-pump, and open cardiac surgery procedures
}

Yasir Abu-Omar, MRCS ${ }^{a}$

Lognathen Balacumaraswami, FRCS ${ }^{a}$

David W. Pigott, FRCA ${ }^{\text {a }}$

Paul M. Matthews, MD, DPhil, FRCP ${ }^{b}$

David P. Taggart, MD, PhD, FRCS ${ }^{\mathrm{a}}$
From the Department of Cardiothoracic Surgery ${ }^{\mathrm{a}}$ and Department for Functional Magnetic Resonance Imaging of the Brain, ${ }^{\text {b }}$ John Radcliffe Hospital, Oxford, United Kingdom.

This project was funded by the British Heart Foundation.

Received for publication June 3, 2003; revisions requested Aug 28, 2003; accepted for publication Sept 16, 2003

Address for reprints: David P. Taggart, MD, PhD, FRCS, Consultant Cardiothoracic Surgeon, Department of Cardiothoracic Surgery, John Radcliffe Hospital, Oxford OX3 9DU, United Kingdom (E-mail: david.taggart@orh.nhs.uk).

J Thorac Cardiovasc Surg 2004;127: $1759-65$

$0022-5223 / \$ 30.00$

Copyright $\odot 2004$ by The American Association for Thoracic Surgery

doi:10.1016/j.jtcvs.2003.09.048
Background: Neurocognitive dysfunction remains a limitation of cardiac surgery with cardiopulmonary bypass. Intraoperative cerebral microembolization is believed to be one of the most important etiologic factors. Using a new generation of transcranial Doppler ultrasonography, we compared the number and nature of intraoperative microemboli in patients undergoing on-pump and off-pump cardiac surgery procedures.

Methods: Bilateral continuous transcranial Doppler monitoring of the middle cerebral arteries was performed in 45 patients (15 off-pump coronary artery bypass grafting, 15 on-pump coronary artery bypass grafting, and 15 open cardiac procedures). All recordings were performed using a multi-range, multifrequency system to allow both measurement of the number and discrimination of the nature of microemboli in the 3 different groups.

Results: The median number (interquartile range) of microemboli in the off-pump coronary artery bypass grafting, on-pump coronary artery bypass grafting, and open procedure groups were 40 (28-80), 275 (199-472), and 860 (393-1321), respectively $(P<.01)$. Twelve percent of microemboli in the off-pump coronary artery bypass grafting group were solid compared with $28 \%$ and $22 \%$ in the on-pump coronary artery bypass grafting and open procedure groups, respectively $(P<.05)$. In the on-pump groups, $24 \%$ of microemboli occurred during cardiopulmonary bypass, and $56 \%$ occurred during aortic manipulation (cannulation, decannulation, application, and removal of crossclamp or sideclamp).

Conclusions: Cerebral microembolization is significantly reduced with avoidance of cardiopulmonary bypass. The majority of microemboli occurring during cardiac surgery are gaseous, with a higher proportion of solid microemboli in the on-pump group, and may have a different significance for cerebral injury than solid microemboli. The ability to reliably discriminate gas and solid microemboli may have an important role in the implementation of neuroprotective strategies.

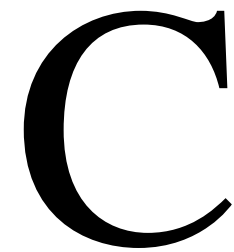
erebral injury is a major cause of mortality and morbidity after cardiac surgery and occurs in 2 distinct forms. Overt injury, usually a stroke, occurs in $3 \%$ of patients undergoing coronary artery bypass grafting (CABG), whereas injury leading to cognitive impairment, only evident on detailed neuropsychologic testing, ${ }^{1-3}$ occurs in up to $80 \%$ of all patients soon after surgery and persists in one quarter of these at 6 months. ${ }^{4}$ Early postoperative cognitive impairment correlates with later progression of cognitive decline and impaired quality of life.,

Cardiopulmonary bypass (CPB) can cause brain injury through several mechanisms, but microembolization is believed to be the most important. Pugsley and 
TABLE 1. Perioperative characteristics

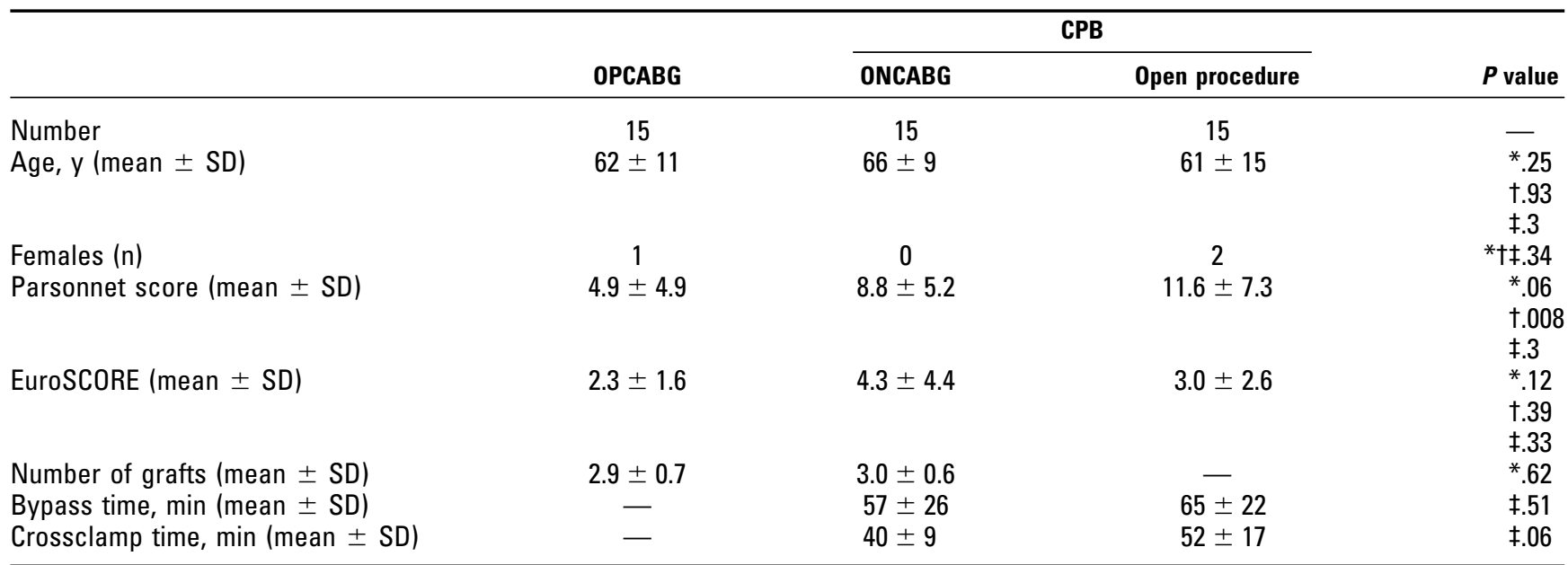

$C A B G$, Coronary artery bypass grafting; OPCABG, off-pump CABG; ONCABG, on-pump CABG; CPB, cardiopulmonary bypass.

${ }^{*}$ Comparison of OPCABG versus ONCABG.

tComparison of OPCABG versus open procedure.

†Comparison of ONCABG versus open procedure.

TABLE 2. Number and proportion of gaseous and solid microemboli detected in three patient groups

\begin{tabular}{lccc}
\hline & \multicolumn{3}{c}{ Microemboli } \\
\cline { 2 - 4 } Procedure & $\begin{array}{c}\text { Total median } \\
(\text { IOR })\end{array}$ & $\begin{array}{c}\text { Gaseous } \\
(\%)\end{array}$ & $\begin{array}{c}\text { Solid } \\
(\%)\end{array}$ \\
\hline OPCABG & $40(28-80)^{*}$ & 88 & $12 \dagger$ \\
ONCABG & $275(199-472)^{*}$ & 72 & $28 \dagger$ \\
Open procedures & $860(393-1321)^{*}$ & 78 & $22 \dagger$
\end{tabular}

$I Q R$, Interquartile range.

*Comparison of the total number of microemboli between the 3 groups: $P$ $<.01$.

tComparison of the proportion of gas and solid microemboli in the 3 groups: $P<.05$.

colleagues $^{7}$ demonstrated that postoperative neuropsychologic deficits are related to the number of cerebral microemboli after routine CPB.

High-intensity transient signals (HITS), detected using transcranial Doppler (TCD) ultrasonography, result from an increase in the ultrasound signal reflected from the microemboli compared with the surrounding blood and can provide an index of microemboli entering the cerebral circulation. However, an increase in the ultrasound signal can also result from artifacts caused by movement. Until recently, it was not possible to differentiate objectively between artifacts and emboli or to discriminate between solid and gaseous microemboli. With the availability of a multifrequency TCD system (EmboDop; DWL Elektronische Systeme $\mathrm{GmbH}$, Singen, Germany), online artifact rejection and automatic discrimination between solid and gaseous microemboli are now achievable with high sensitivity and specific- ity. ${ }^{8,9}$ This technique depends on insonating an embolus using 2 different frequencies. A solid embolus would reflect more ultrasound at the higher compared with the lower frequency, whereas the opposite occurs with gaseous microemboli. This study quantified the number and nature of intraoperative microemboli in patients undergoing various cardiac surgery procedures.

\section{Material and Methods Patient Groups}

A total of 45 patients undergoing first-time cardiac surgery were prospectively recruited for the study. All patients gave informed consent, and full ethical approval was obtained from the local research ethics committee (Oxford Research Ethics Committee number C01.258). The patients were divided into 3 groups. Fifteen patients underwent off-pump CABG (OPCABG), 15 patients underwent on-pump CABG (ONCABG), and the remaining 15 patients underwent valve replacement with or without $\mathrm{CABG}$ : aortic valve replacement (12 patients), aortic valve replacement and CABG (2 patients), and mitral valve replacement and CABG (1 patient). Patients with symptomatic carotid disease or atrial fibrillation were excluded.

\section{CPB}

After full anticoagulation with heparin given at a dose of 300 IU/kg to maintain an activated clotting time of 400 to 600 seconds, CPB was instituted using ascending aortic cannulation and a 2-stage right atrial venous cannulation. A roller pump (Jostra HL 20, Hirrlingen, Germany) and hollow-fiber membrane oxygenator (Affinity NT; Medtronic Inc, Minneapolis, Minn) were used. The extracorporeal circuit was primed with $1000 \mathrm{~mL}$ of Hartmann's solution and 2500 IU of heparin. CPB was maintained with nonpulsatile flow with a flow rate of $2.4 \mathrm{~L} / \mathrm{m}^{2} / \mathrm{min}$ at normothermia with the temperature allowed to drift to $34^{\circ} \mathrm{C}$. Arterial line filtra- 


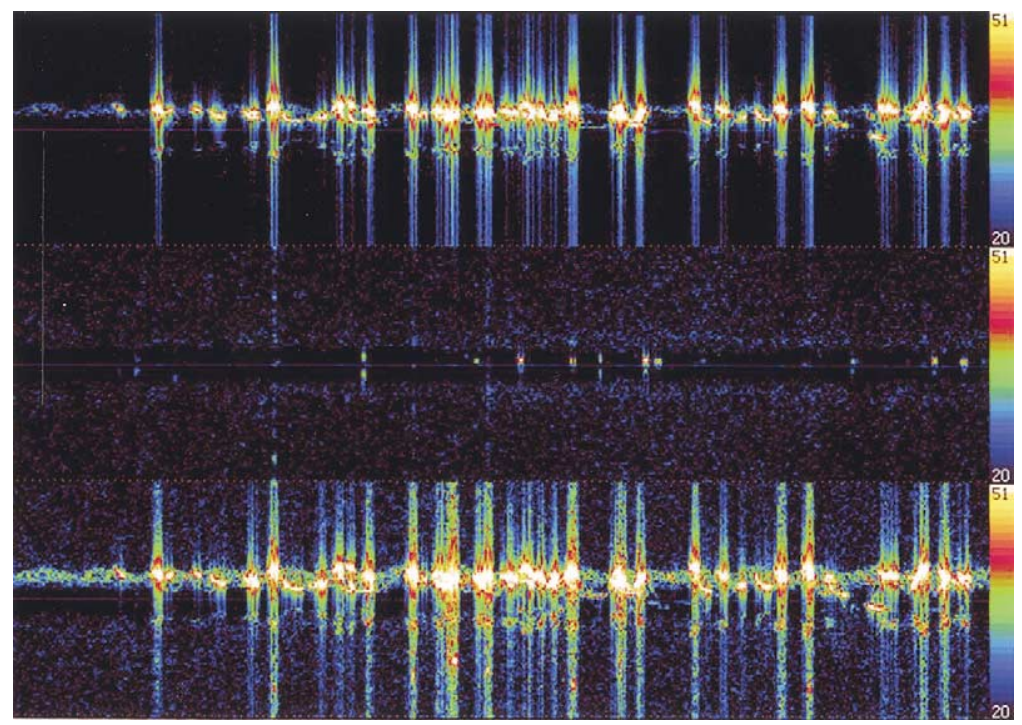

Figure 1A. HITS seen after aortic crossclamp removal. The top and bottom traces represent the 2.0 and $2.5 \mathrm{MHz}$ middle cerebral artery gates, respectively. The middle trace represents the $2.0 \mathrm{MHz}$ reference gate.

tion was not used. Cardiotomy suction was used. Acid-base was managed with alpha stat control. Myocardial protection was achieved with intermittent antegrade cold crystalloid cardioplegia. On completion of all distal anastomoses, the aortic crossclamp was removed, and the proximal anastomosis was performed with partial aortic clamping.

\section{Off-Pump Technique}

Complete anticoagulation with heparin was achieved as in the CPB group. Regional myocardial immobilization was achieved with a suction stabilizer (Octopus, Medtronic Inc or Guidant; Guidant Corporation, Santa Clara, Calif). The target coronary vessels were snared proximally with a silastic sling. An intracoronary shunt (Guidant Axius) was used only when there was hemodynamic compromise during construction of the anastomosis (usually the distal right coronary artery). Visualization was enhanced by using a surgical blower-mister device (Medtronic Clearview, Medtronic Inc). All patients had composite arterial grafts with complete avoidance of aortic manipulation.

\section{TCD Monitoring}

Continuous intraoperative monitoring was performed using a multifrequency Doppler system (Embodop, DWL). Dual frequency probes $(2.0$ and $2.5 \mathrm{MHz}$ ) were used to simultaneously insonate the middle cerebral arteries (MCAs) bilaterally. The probes were fixed to the transtemporal windows above the right and left zygomatic arches using a specifically designed head brace. The MCA insonation depth was set between 45 and $55 \mathrm{~mm}$ with a sample volume of $13 \mathrm{~mm}$. An additional $2.0 \mathrm{MHz}$ insonation reference gate was set $15 \mathrm{~mm}$ superficial to the MCA insonation gate. This reference gate serves for the online rejection of artifacts because the latter are identified when HITS are detected in both gates (MCAs and reference gates) simultaneously or with a time delay of less than 4 milliseconds.

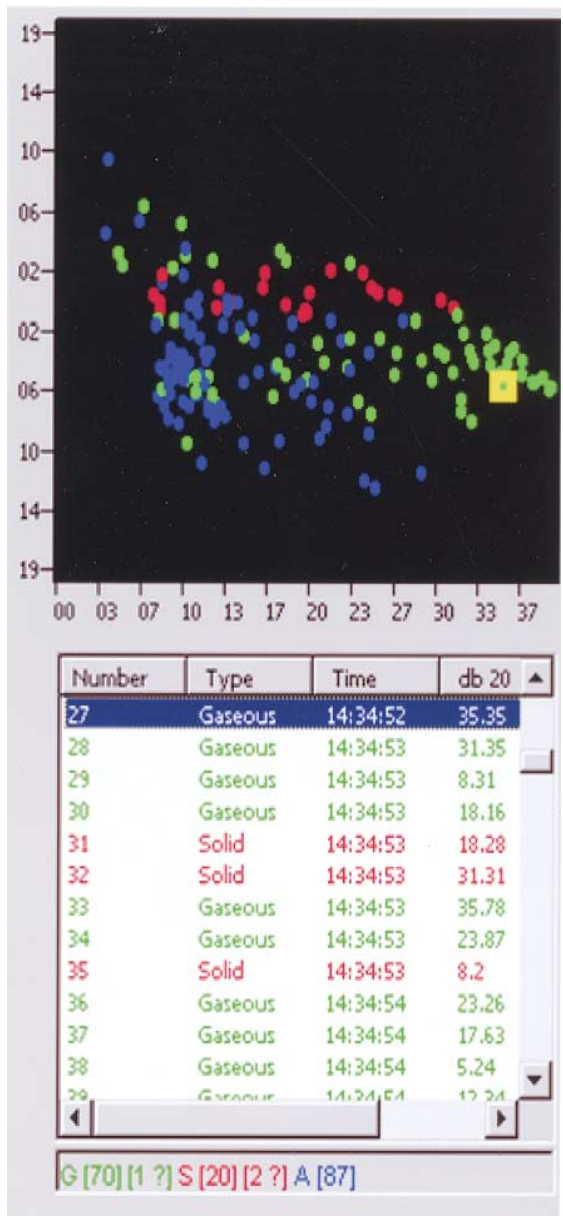

Figure 1B. Rejection of artifacts and differentiation into gaseous and solid microemboli during off-line analysis. 
This multifrequency system (2.5 MHz and 2.0 MHz) also differentiates between solid and gaseous microemboli. Solid microemboli reflect more ultrasound at higher than at lower frequencies, contrary to what occurs in the case of gaseous microemboli. The differentiation occurs online during monitoring, and the data are recorded on a computer hard drive that also allows off-line analysis to be performed.

\section{Statistical Analysis}

Patient characteristics are presented as mean \pm SD. Normally distributed data were compared using the Student $t$ test. Categoric variables were compared using the $\chi^{2}$ test. The number of HITS is presented as median and interquartile ranges. Because the data are not normally distributed, the nonparametric Kruskal-Wallis test was used to compare the difference in microembolization among the 3 groups.

\section{Results}

Patient characteristics are summarized in Table 1.

Only around $10 \%$ of all HITS were microemboli, with the remaining $90 \%$ being rejected as artifacts. The median (interquartile range) number of microemboli was 40 (28-80) in the OPCABG group, 275 (199-472) in the ONCABG group, and 860 (393-1321) in the open procedure group $(P$ $<.01$ ) (Table 2).

Solid microemboli accounted for $12 \%$ of all microemboli in the OPCABG group compared with $28 \%$ and $22 \%$ in the ONCABG and open procedure groups, respectively. The proportion of particulate microemboli was significantly higher in the on-pump groups compared with the OPCABG group $(P<.05)$ (Table 2$)$.

In the on-pump group, the largest proportion of microemboli occurred during aortic manipulation (cannulation, decannulation, and application and removal of crossclamp and sideclamp (Figure 1), accounting for $56 \%$ of the total, whereas $24 \%$ occurred during CPB (Table 3 ). The extent of gaseous and solid microembolization during the different stages of OPCABG, ONCABG, and open procedures is shown in Figures 2, 3, and 4.

\section{Discussion}

Our study adds to the understanding of the pathophysiology of microemboli during cardiac surgery by using a new generation of TCD that automatically rejects artifacts and discriminates between gaseous and solid microemboli. Comparison of cerebral microembolization in on-pump versus off-pump procedures has been reported. ${ }^{10}$ However, this is the first report contrasting the nature of microemboli in ONCABG, OPCABG, and open procedures. In comparison with OPCABG, there is a 7-fold increase in microemboli in ONCABG and a 22 -fold increase in open procedures. Furthermore, the proportion of solid microemboli was significantly reduced in the off-pump group.

Cerebral microemboli have been implicated in the pathogenesis of cognitive decline after CPB for more than a decade. $^{7,11,12}$ Various reports have demonstrated a positive association between the number of intraoperative cerebral microemboli detected by TCD and postoperative neuropsychologic dysfunction. In addition, autopsy studies have reported large numbers of lipid microemboli in the brains of patients dying after cardiac surgery that correlated with the duration of $\mathrm{CPB} .{ }^{13}$

A recent report demonstrated a significant reduction in the incidence of neuropsychologic impairment with avoidance of CPB. ${ }^{14}$ Our study demonstrates the remarkable reduction in the degree of microembolization, both gas and solid, during OPCABG. This may account for the difference in neuropsychologic impairment reported between patients undergoing on-pump and off-pump procedures. ${ }^{10,14}$ The clinical consequences, however, may be equally dependent on the nature and number of microemboli identified using TCD.

Particulate microemboli are generally assumed to be potentially the most damaging. Until recently, it was not possible to distinguish between gaseous and solid microemboli. We used a recently validated method ${ }^{9}$ to identify the variation in the degree and nature of microembolism during different cardiac surgery procedures. In addition, this technique allows automatic online rejection of artifacts, whereas previously the human observer was regarded as the "gold standard." Gaseous microemboli as small as $3 \mu \mathrm{m}$ and solid microemboli of $80 \mu \mathrm{m}$ in diameter can be reliably detected. ${ }^{9}$ The demonstration of the increase in particulate embolic load to the brain of patients undergoing CPB highlights the potential of the latter for causing cerebral injury, which is most likely to be evident in higher risk patients. The avoidance of CPB and aortic manipulation in the latter group has been shown to significantly reduce postoperative neurologic complications. ${ }^{15,16}$

What is the source of microemboli during OPCABG? Although microemboli can be detected in the cerebral circulation using TCD, the origin of these microemboli remains speculative. In the case of total arterial revascularization using composite arterial grafts (a "no-touch" aortic technique), a likely source of gaseous microemboli is air entering the coronary artery during arteriotomy and being returned to the left ventricle through the Thebesian veins. Another potential source of gas microemboli is through injections into central venous lines. Microemboli in the right side of the heart may then enter the systemic circulation by paradoxic embolism through a patent foramen ovale (present in up to $35 \%$ of the healthy population ${ }^{17}$ ) or after transpulmonary passage. These mechanisms may also explain why cerebral microembolization occurs during major non-cardiac surgery procedures, particularly during major orthopedic operations. ${ }^{18,19}$

Particulate microemboli may form within the heart, particularly the left atrial appendage and left ventricle. In 


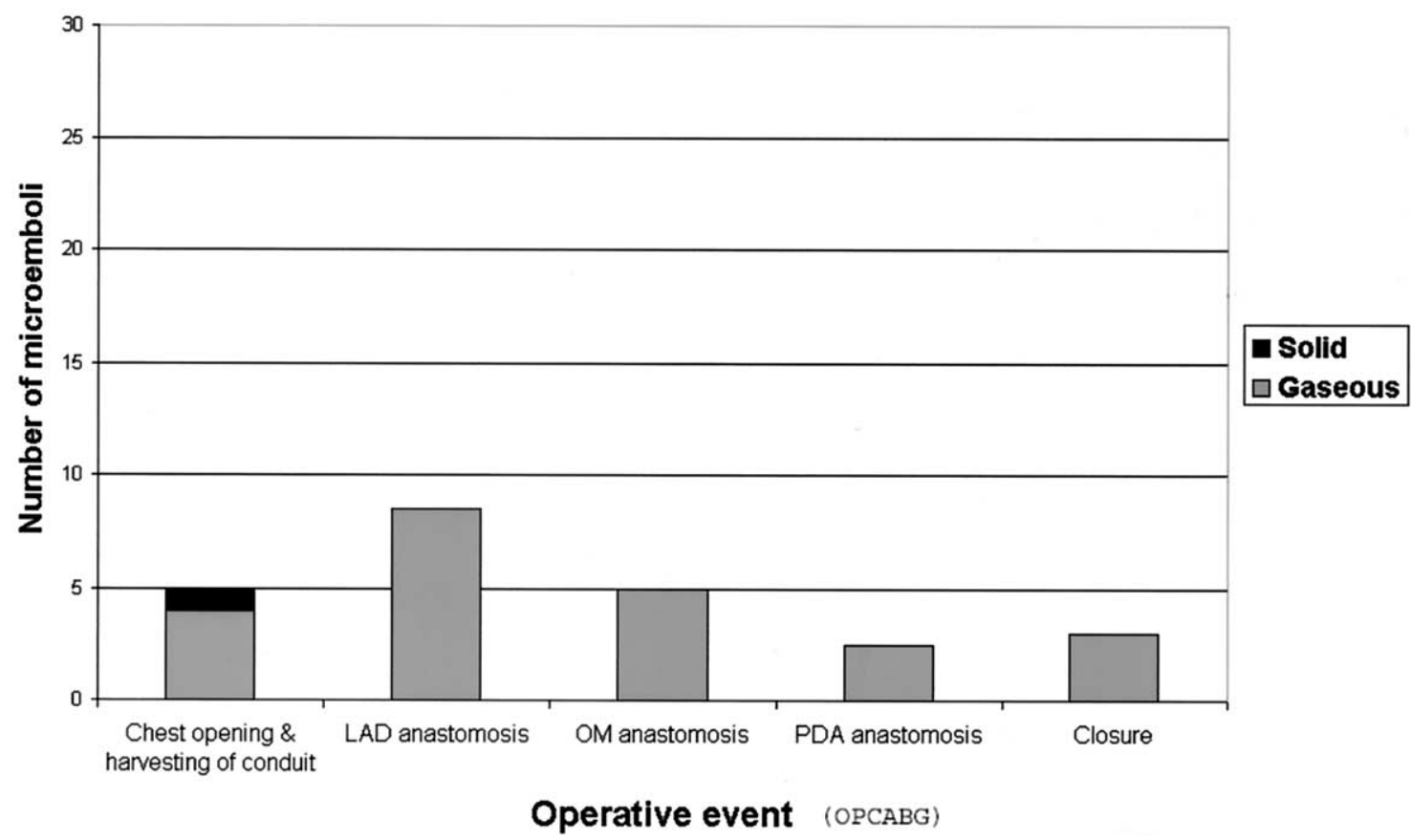

Figure 2. Gaseous and solid microembolization during the course of OPCABG. LAD, Left anterior descending; OM, obtuse marginal; PDA, posterior descending artery.

TABLE 3. Number and proportion of microemboli during different operative events in patients undergoing on-pump surgery

\begin{tabular}{|c|c|c|c|c|c|c|}
\hline \multirow[b]{2}{*}{ Operative event } & \multicolumn{2}{|c|}{ Total gas and solid } & \multicolumn{2}{|c|}{ Gaseous } & \multicolumn{2}{|c|}{ Solid } \\
\hline & Median (IOR) & $\begin{array}{l}\text { Percentage of } \\
\text { total }\end{array}$ & Median (IOR) & $\begin{array}{l}\text { Percentage of } \\
\text { total gas }\end{array}$ & $\begin{array}{l}\text { Median } \\
\text { (IOR) }\end{array}$ & $\begin{array}{l}\text { Percentage of } \\
\text { total solids }\end{array}$ \\
\hline Aortic cannulation and crossclamping & $26(8-67)$ & $13 \%$ & $41(20-100)$ & $13 \%$ & $8(3-30)$ & $12 \%$ \\
\hline During CPB & $145(60-265)$ & $24 \%$ & $108(43-199)$ & $24 \%$ & $24(9-76)$ & $26 \%$ \\
\hline $\begin{array}{l}\text { Removal of aortic crossclamp, } \\
\text { sideclamping, decannulation }\end{array}$ & $148(56-504)$ & $43 \%$ & $123(43-381)$ & $42 \%$ & $31(6-135)$ & $46 \%$ \\
\hline $\begin{array}{l}\text { Other (chest opening and closure, } \\
\text { harvesting of conduits) }\end{array}$ & $11(2-68)$ & $20 \%$ & $6(1-59)$ & $21 \%$ & $2(0-8)$ & $16 \%$ \\
\hline
\end{tabular}

on-pump cases, they can form within the bypass circuit if anticoagulation is inadequate. Cholesterol microemboli probably arise from the atherosclerotic aorta during manipulation, ${ }^{20}$ whereas use of the cardiotomy suction and denaturation of proteins may result in lipid microembolization during $\mathrm{CPB} .{ }^{21}$ Furthermore, platelet and blood cell aggregation occurring during CPB may add to this microembolic load. Gaseous microemboli may enter the circulation during flushing and filling of coronary conduits, at initiation of $\mathrm{CPB}$, through the bypass circuit after blood sampling and injection of drugs, and during cardiac ejection after open procedures. ${ }^{22}$ The increase in absolute numbers of gaseous microemboli during open procedures is consistent with transesophageal echocardiographic findings even after vigorous de-airing proce- dures. ${ }^{23}$ It must be noted, however, that differentiation and quantitation of HITS is difficult when a large number of microemboli pass through the sample volume simultaneously such as after removal of the aortic crossclamp or sideclamp. ${ }^{8}$ This, however, serves to underestimate the benefits of OPCABG in which there is a lack of such embolic showers entering the sample volume simultaneously.

Cerebral injury remains one of the most important causes of adverse outcomes after cardiac surgery. It particularly affects elderly patients and those with other comorbidities and is more common and severe after cardiac operations performed using CPB.${ }^{14}$ As a progressively older and sicker population undergoes both cardiac and noncardiac surgery procedures, the scale of the problem is likely to increase. 


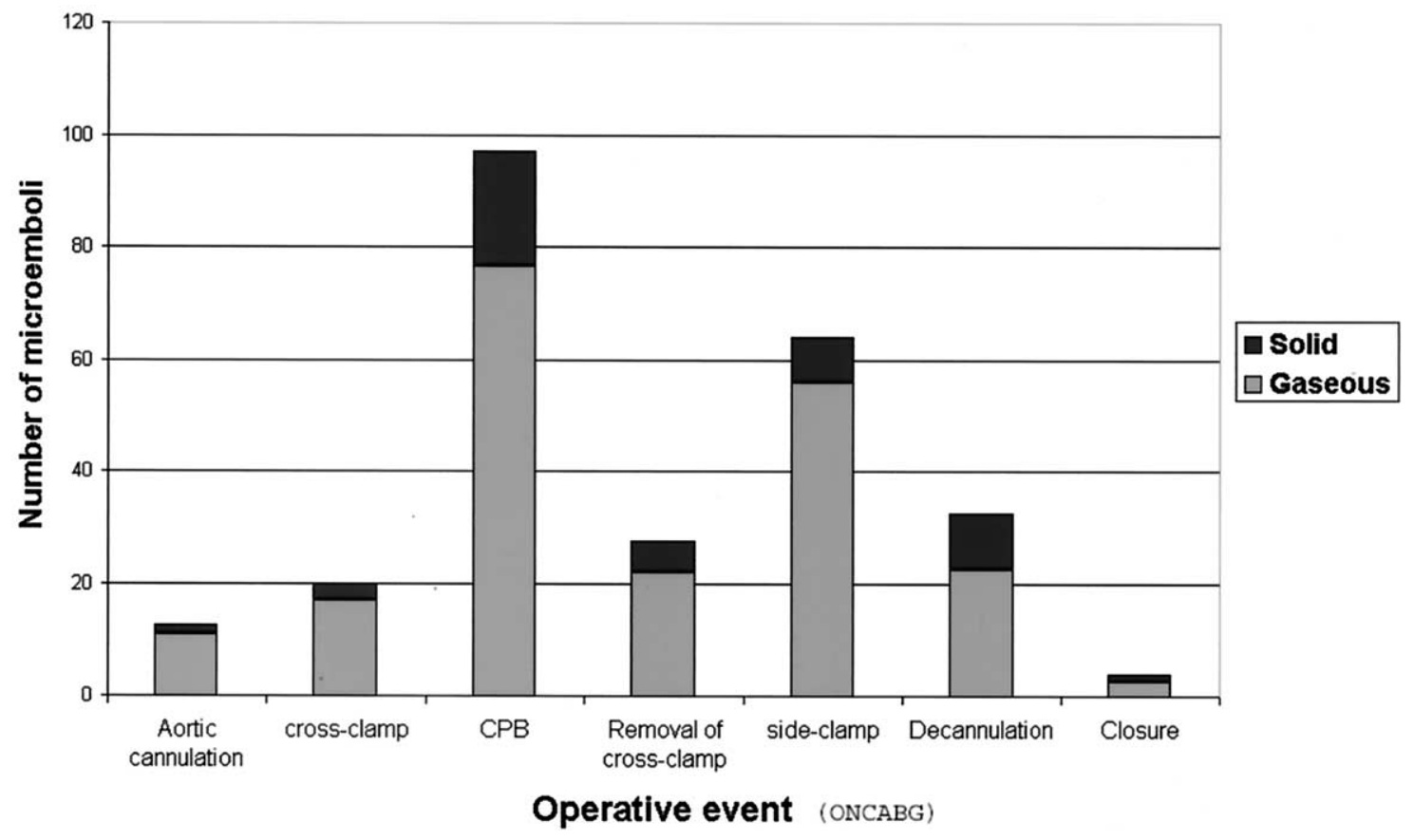

Figure 3. Gaseous and solid microembolization during the course of ONCABG. CPB, Cardiopulmonary bypass.

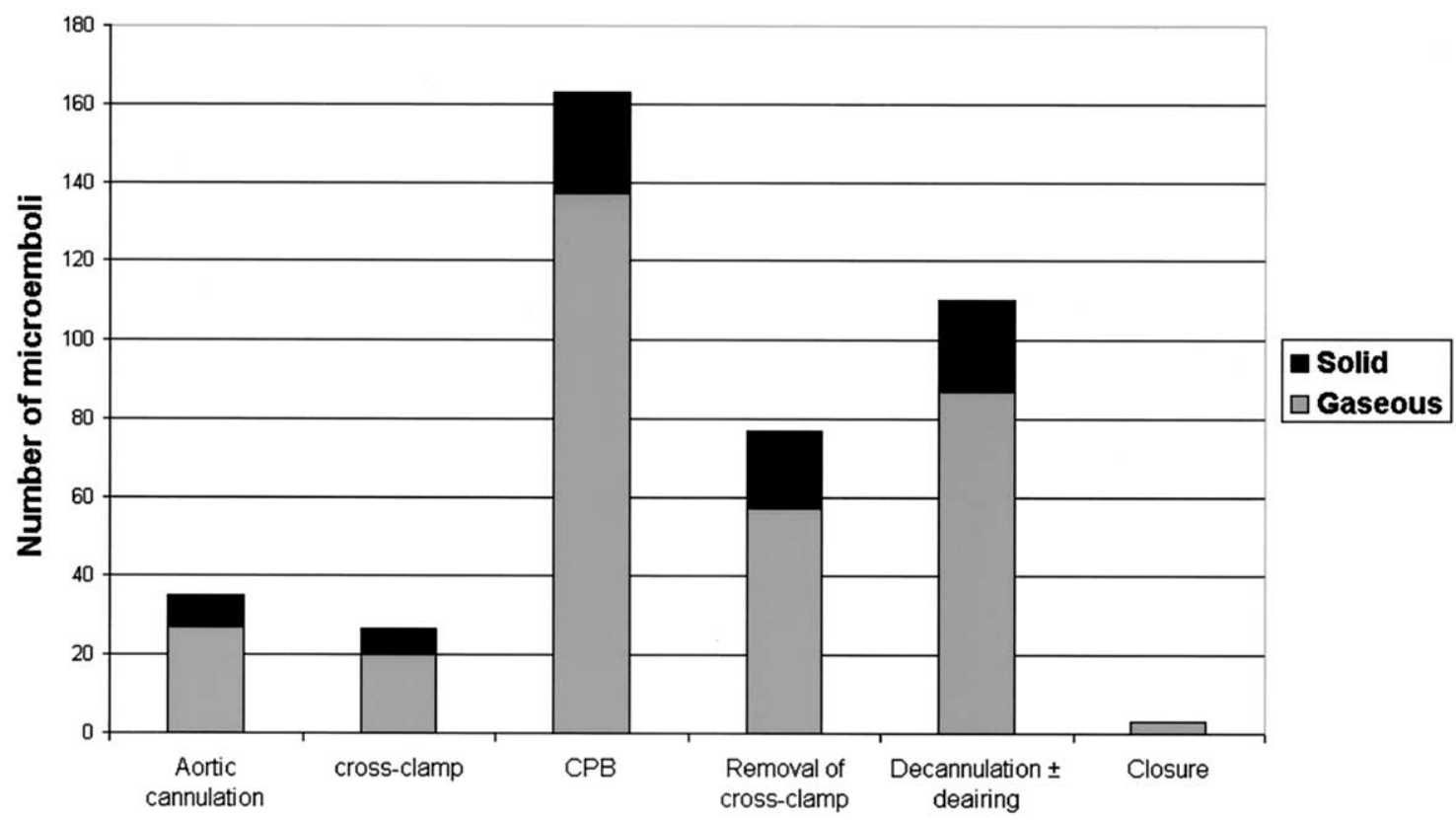

Operative event (Open-heart)

Figure 4. Gaseous and solid microembolization during the course of an open procedure. CPB, Cardiopulmonary bypass.

Indeed, we and others have documented that advanced age is the strongest predictor of postoperative neurocognitive impairment. ${ }^{3}$

\section{Conclusion}

Cerebral embolization remains a problem during CPB. This can be minimized by performing off-pump surgery with 
avoidance of aortic manipulation. The ability to reliably discriminate the nature of cerebral microemboli has an important potential role in targeting various prevention strategies to improve neurologic outcome after cardiac operations, particularly de-airing after open procedures.

\section{References}

1. Taggart DP, Browne SM, Halligan PW, Wade DT. Is cardiopulmonary bypass still the cause of cognitive dysfunction after cardiac operations? J Thorac Cardiovasc Surg. 1999;118:414-21.

2. Browne SM, Halligan PW, Wade DT, Taggart DP. Cognitive performance after cardiac operation: implications of regression toward the mean. J Thorac Cardiovasc Surg. 1999;117:481-5.

3. Taggart DP, Westaby S. Neurological and cognitive disorders after coronary artery bypass grafting. Curr Opin Cardiol. 2001;16:271-6.

4. van Dijk D, Keizer AM, Diephuis JC, Durand C, Vos LJ, Hijman R. Neurocognitive dysfunction after coronary artery bypass surgery: a systematic review. J Thorac Cardiovasc Surg. 2000;120:632-9.

5. Newman MF, Kirchner JL, Phillips-Bute B, Gaver V, Grocott H, Jones $\mathrm{RH}$, et al. Longitudinal assessment of neurocognitive function after coronary-artery bypass surgery. N Engl J Med. 2001;344:395-402.

6. Newman MF, Grocott HP, Mathew JP, White WD, Landolfo K, Reves JG, et al. Report of the substudy assessing the impact of neurocognitive function on quality of life 5 years after cardiac surgery. Stroke. 2001;32:2874-81.

7. Pugsley W, Klinger L, Paschalis C, Treasure T, Harrison M, Newman $\mathrm{S}$. The impact of microemboli during cardiopulmonary bypass on neuropsychological functioning. Stroke. 1994;25:1393-9.

8. Brucher R, Russell D. Automatic online embolus detection and artifact rejection with the first multifrequency transcranial Doppler. Stroke. 2002;33:1969-74.

9. Russell D, Brucher R. Online automatic discrimination between solid and gaseous cerebral microemboli with the first multifrequency transcranial Doppler. Stroke. 2002;33:1975-80.

10. Diegeler A, Hirsch R, Schneider F, Schilling LO, Falk V, Rauch T, et al. Neuromonitoring and neurocognitive outcome in off-pump versus conventional coronary bypass operation. Ann Thorac Surg. 2000;69: 1162-6.

11. Stump DA, Rogers AT, Hammon JW, Newman SP. Cerebral emboli and cognitive outcome after cardiac surgery. J Cardiothorac Vasc Anesth. 1996;10:113-9.

12. Sylivris S, Levi C, Matalanis G, Rosalion A, Buxton BF, Mitchell A, et al. Pattern and significance of cerebral microemboli during coronary artery bypass grafting. Ann Thorac Surg. 1998;66:1674-8.

13. Brown WR, Moody DM, Challa VR, Stump DA, Hammon JW. Longer duration of cardiopulmonary bypass is associated with greater numbers of cerebral microemboli. Stroke. 2000;31:707-13.

14. Zamvar V, Williams D, Hall J, Payne N, Cann C, Young K, et al. Assessment of neurocognitive impairment after off-pump and onpump techniques for coronary artery bypass graft surgery: prospective randomised controlled trial. BMJ. 2002;325:1268.

15. Ricci M, Karamanoukian HL, Abraham R, Von Fricken K, D'Ancona G, Choi S, et al. Stroke in octogenarians undergoing coronary artery surgery with and without cardiopulmonary bypass. Ann Thorac Surg. 2000;69:1471-5.

16. Kim KB, Kang CH, Chang WI, Lim C, Kim JH, Ham BM, et al. Off-pump coronary artery bypass with complete avoidance of aortic manipulation. Ann Thorac Surg. 2002;74:S1377-82.

17. Meacham RR 3rd, Headley AS, Bronze MS, Lewis JB, Rester MM. Impending paradoxical embolism. Arch Intern Med. 1998;158:438-48.

18. Sulek CA, Davies LK, Enneking FK, Gearen PA, Lobato EB. Cerebral microembolism diagnosed by transcranial Doppler during total knee arthroplasty: correlation with transesophageal echocardiography. Anesthesiology. 1999;91:672-6.

19. Edmonds CR, Barbut D, Hager D, Sharrock NE. Intraoperative cerebral arterial embolization during total hip arthroplasty. Anesthesiology. 2000;93:315-8.

20. Barbut D, Hinton RB, Szatrowski TP, Hartman GS, Bruefach M, Williams-Russo P, et al. Cerebral emboli detected during bypass surgery are associated with clamp removal. Stroke. 1994;25:2398402.

21. Brooker RF, Brown WR, Moody DM, Hammon JW Jr, Reboussin DM, Deal DD, et al. Cardiotomy suction: a major source of brain lipid emboli during cardiopulmonary bypass. Ann Thorac Surg. 1998;65: 1651-5.

22. Blauth CI. Macroemboli and microemboli during cardiopulmonary bypass. Ann Thorac Surg. 1995;59:1300-3.

23. Tingleff J, Joyce FS, Pettersson G. Intraoperative echocardiographic study of air embolism during cardiac operations. Ann Thorac Surg. 1995;60:673-7. 